\title{
FINITE ELEMENT-BASED FATIGUE BEHAVIOUR OF SPRINGS IN AUTOMOBILE SUSPENSION
}

\author{
M. Kamal ${ }^{1}$ and M. M. Rahman ${ }^{1,2}$ \\ ${ }^{1}$ Faculty of Mechanical Engineering, Universiti Malaysia Pahang, \\ 26600 Pekan, Pahang, Malaysia \\ ${ }^{2}$ Automotive Engineering Centre, Universiti Malaysia Pahang \\ 26600 Pekan, Pahang, Malaysia \\ Email: mustafizur@ump.edu.my \\ Phone" +6094246239; Fax: +6094246222
}

\begin{abstract}
This paper presents the fatigue behaviour of springs used in shock absorbers in automobile suspension systems. SAE 9254 is considered as a spring material. Triangular waves with a frequency of $4 \mathrm{~Hz}$ and SAE standard suspension loading history (SAESUS) were used for fatigue analysis. Both load histories are scaled according to the maximum and minimum values of deflection, as spring height at full-bump and full-rebound, respectively. Finite element analysis was carried out using the linear static approach. Fatigue analysis was performed using the strain-life method. Absolute maximum principal and critical plane approaches gave results of reasonable accuracy, but later had a considerably longer solution time, while signed von Mises and signed shear approaches gave very conservative results. Thus the absolute maximum principal method is found to be the best suited. The results show that the spring did not fail before $4 \times 10^{5}$ cycles at $4 \mathrm{~Hz}$ for wave time history and 70,000 repeats for SAESUS time history at critical location.
\end{abstract}

Keywords: Strain-life method, spring, suspension system, variable amplitude loading, FEA.

\section{INTRODUCTION}

Nowadays vehicle design is under some conflicting demands (for example, vehicles must be lightweight and also have good reliability). There is increasing pressure in the automotive industry to reduce the time taken to bring new designs to production[1-3]. At the same time it is necessary for the vehicles being developed to have the right attributes such as durability and low weight in order to remain competitive [4-8]. In automotive companies, creating new and improved designs can give a significant competitive edge and define the success or failure of an entire product line [9]. The suspension system is responsible for absorbing the shock loads produced by road disturbances [3, 10-12]. It consists of three types of components: the spring is the force-bearing member; the damper is the oscillation-damping member and the structural member. A major design concern is fatigue failure for suspension systems - to qualify, a design must not fail under fatigue when facing predefined design loading conditions [13]. The spring is made from the steel alloy SAE 9254, which is commonly used in manufacturing coil springs. The design information of the spring is available in the form of engineering drawings [14]. In this study, fatigue analysis was conducted using the strain-life method under variable amplitude loading conditions. First a loading history was generated from the fatigue test 
information mentioned in the spring design as a triangular wave of $4 \mathrm{~Hz}$ frequency, and a second loading history used is standard SAESUS. Both histories were scaled and trimmed according to the maximum and minimum deflection (full bump and full rebound, respectively) in the design. The aim of this paper is to predict the fatigue behaviour of springs in automobile suspension using the finite element analysis approach.

\section{METHODS AND MATERIALS}

\section{Finite Element Method}

The structural model, as well as the finite element model, is developed using ANSYS analysis code. Figure 1 shows the finite element model and boundary conditions of the springs of a suspension system. The compression load is applied through two rigid surfaces and the spring is meshed with 20 node brick elements. Thus the circular wire and coil geometry can be simulated correctly; compressing surfaces are meshed with shell elements [3]. The load is applied as a displacement which causes the deformation of the spring from a free length (no load) of $392 \mathrm{~mm}$ to the height of $185 \mathrm{~mm}$ mentioned in the design [14]. Stresses and strains from the structural analysis are used as representative of stress field in the spring in the fatigue analysis. The simulation is set up with the contact definition as a bonded contact between the compression surface and the spring, and the deformation is applied in steps to facilitate the convergence of a solution. The results of the stress analysis are transferred to fatigue analysis software to predict the fatigue behaviour of the spring under cyclic loading [13]. The required material parameters depend on the analysis methodology being used. The material is considered as elastic and isotropic. The mechanical properties of the SAE 9254 spring steel alloy are shown in Table 1. [15].

Table 1. Monotonic and cyclic properties of SAE 9254 spring steel

\begin{tabular}{lcc}
\hline Monotonic properties & Value & Unit \\
\hline Young's Modulus $(\mathrm{E})$ & 205.4 & $\mathrm{GPa}$ \\
Yield strength $\left(\sigma_{\mathrm{y}}\right)$ & 2270 & $\mathrm{MPa}$ \\
Ultimate strength $\left(\sigma_{\mathrm{u}}\right)$ & 2950 & $\mathrm{MPa}$ \\
Fracture strain $\left(\varepsilon_{\mathrm{f}}\right)$ & $4.08 \%$ & \\
Fracture stress $\left(\sigma_{\mathrm{t}}\right)$ & 2483 & $\mathrm{MPa}$ \\
Strength coefficient $(\mathrm{K})$ & 2916 & $\mathrm{MPa}$ \\
Strain hardening exponent $(\mathrm{n})$ & 0.0418 & \\
\hline Cyclic properties & & \\
\hline Cyclic yield strength $\left(\sigma_{\mathrm{y}}\right)$ & 1922 & $\mathrm{MPa}$ \\
Cyclic strength coefficient $\left(\mathrm{K}^{\prime}\right)$ & 3322 & $\mathrm{MPa}$ \\
Cyclic strain hardening exponent $\left(\mathrm{n}^{\prime}\right)$ & 0.088 & \\
Fatigue strength coefficient $\left(\sigma_{\mathrm{t}}^{\prime}\right)$ & 4108 & $\mathrm{MPa}$ \\
Fatigue strength exponent $(\mathrm{b})$ & -0.109 & \\
Fatigue ductility coefficient $\left(\varepsilon_{\mathrm{t}}^{\prime}\right)$ & 1.13 & \\
Fatigue ductility exponent $(\mathrm{c})$ & -0.954 & \\
\hline
\end{tabular}

Mesh sensitivity analysis was performed on the FE model to get the appropriate size of the mesh which has a realisable balance between accuracy and cost (CPU time)[16-19]. For the analysis, specific variables and structural error in FE solution is monitored and 
evaluated.

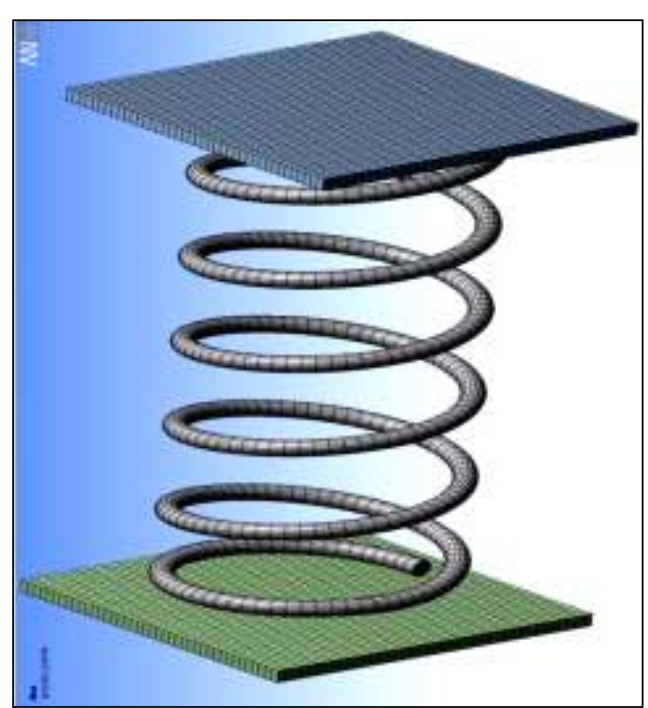

(a) Hex20 elements

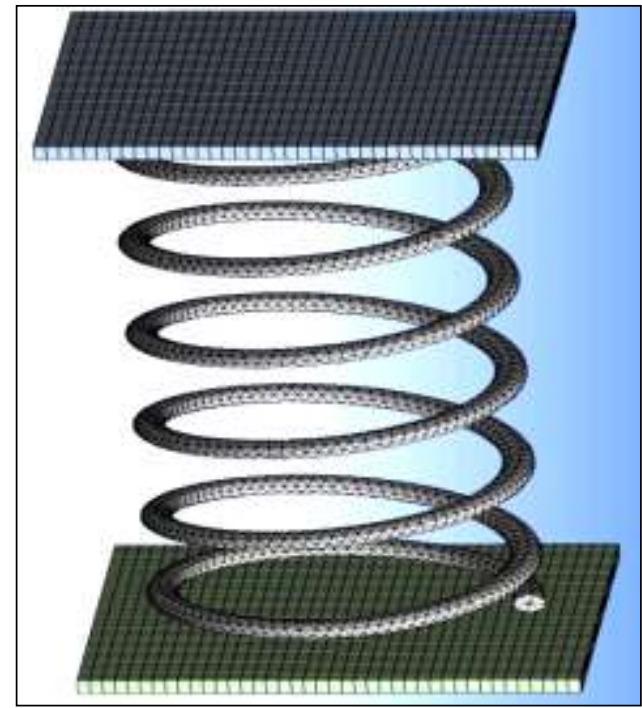

(b) Tet10 elements

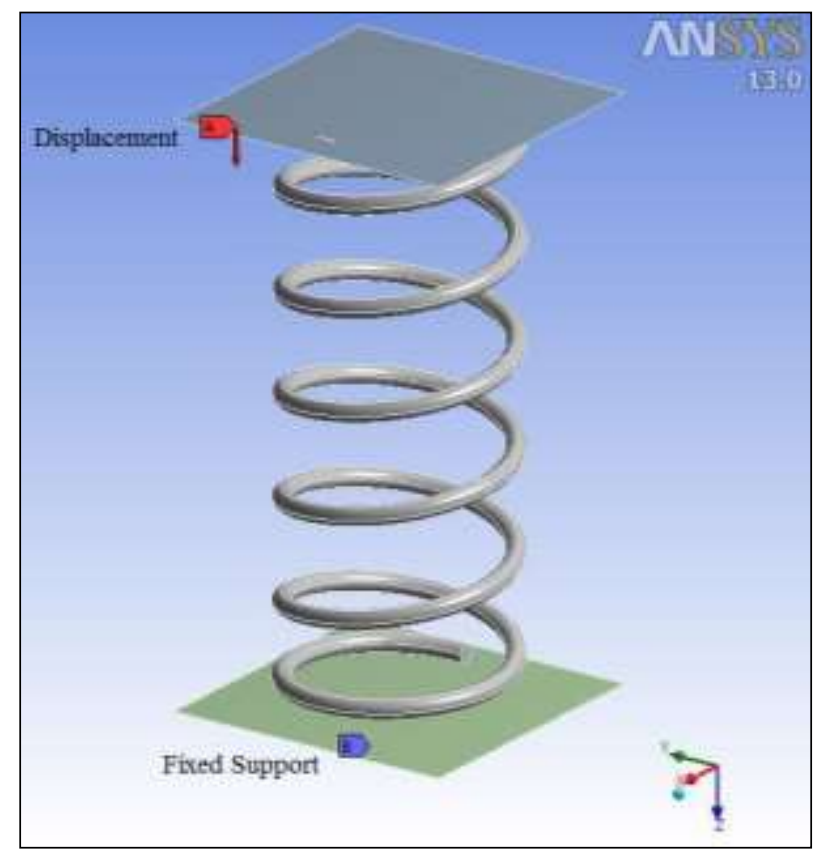

(c) Boundary conditions

Figure 1. Finite element model and boundary conditions

The hexahedral meshing approach is applied for meshing of spring geometry, tetrahedral meshing is also studied for comparison between the two mesh types [3]. The hexahedral elements (HEX20) and tetrahedral element (TET10) are used (Figure 1). It can be seen that hexahedral and tetrahedral mesh are predicted in terms of von Mises, Tresca and maximum principal stress values within a close difference, as shown in Table 2. A comparison was made between the structural errors. It can be seen that HEX20 elements of nearly same size predicted the results with much more accuracy than TET10. The larger HEX20 element size causes a considerable difference in the structural error 
being induced. The convergence of the stress is considered as the main criteria for selecting the mesh type and size. Table 2 shows the results at the critical location (see Figure 2), it can be seen that HEX20 with a $0.007 \mathrm{~m}$ sweep mesh and a $0.0025 \mathrm{~m}$ face mesh has the best structural error and CPU time combination. A smaller HEX20 mesh size has a lower structural error but is not implemented due to a large increase in CPU time, storage capacity and memory requirement. Hence HEX20 mesh with a $0.007 \mathrm{~m}$ element size and $0.0025 \mathrm{~m}$ face mesh size is used in the fatigue life analysis.

Table 2. Variation of mesh size and stress results for Hex20 and Tet10 mesh

\begin{tabular}{ccccccc}
\hline Mesh & Total & Total & \multicolumn{3}{c}{ Stress (MPa) } & Structural \\
\cline { 4 - 6 }$(\mathrm{mm})$ & nodes & elements & $\begin{array}{c}\text { von } \\
\text { Mises }\end{array}$ & Tresca & $\begin{array}{c}\text { Max. } \\
\text { Principal }\end{array}$ & $\begin{array}{c}\text { Eror } \\
\left(\times 10^{-6}\right)\end{array}$ \\
\hline \multicolumn{6}{c}{ For HEX20 Mesh } \\
\hline 0.005 & 157,151 & 36,800 & 1478 & 1705 & 778.24 & 1.137 \\
0.007 & 62,527 & 15,184 & 1479.3 & 1705.9 & 776.47 & 3.972 \\
0.01 & 20,862 & 6,511 & 1521.9 & 1755 & 798.3 & 186.2 \\
0.013 & 13,136 & 4,824 & 1516.1 & 1748.3 & 794.59 & 266.9 \\
0.016 & 11,330 & 4,523 & 1519.8 & 1752.6 & 794.11 & 382.8 \\
\hline \multicolumn{6}{c}{ For TET10 Mesh } \\
\hline 0.004 & 54,454 & 26,668 & 1481.9 & 1708.4 & 778.27 & 186 \\
0.005 & 42,419 & 1,967 & 1466.3 & 1690.8 & 774.6 & 2693 \\
\hline \multicolumn{7}{c}{}
\end{tabular}

\section{Strain-life Method}

The local strain-life approach is considered when the loading history is random and where the mean stress and the load sequence effects are thought to be of importance. This approach involves techniques for converting the loading history, geometry and material property (monotonic and cyclic) inputs into a fatigue life prediction [20]. First, the stress and strain in the critical region are estimated and then the rainflow cycle counting method [21] is used to reduce the load-time history. The next step is to use the finite element method to convert the reduced load-time history into a strain-time history, and to calculate the stress and strain in the highly stressed area. Then, the crack initiation methods are employed to predict the fatigue life. The simple linear hypothesis proposed by Palmgren [22] and Miner [23] is used to accumulate the fatigue damage. Finally, the damage values for all cycles are summed until a critical damage sum (failure criteria) is reached. In this study, the strain life analysis method is used to estimate fatigue life. The fatigue resistance of metals can be characterised by a strain-life curve. The relationship between the total strain amplitude $(\Delta \varepsilon / 2)$ and the reversals to failure $\left(2 \mathrm{~N}_{f}\right)$ can be mathematically expressed as Eq. (1) [20].

The Coffin Mason Model:

$$
\varepsilon_{a}=\frac{\sigma_{f}^{\prime}}{E}\left(2 N_{f}\right)^{p}+\varepsilon_{f}^{\prime}\left(2 N_{f}\right)^{c}
$$

where $N_{f}$ is the fatigue life, $\sigma_{f}^{\prime}$ is the fatigue strength coefficient, $E$ is the modulus of elasticity, $b$ is the fatigue strength exponent, $\varepsilon_{f}$ is the fatigue ductility coefficient, and $c$ is the fatigue ductility exponent. 
The absolute maximum principal strain method is used to combine component strains:

$$
\varepsilon_{A M P}=\varepsilon_{3} \text { if }\left|\varepsilon_{3}\right|>\left|\varepsilon_{1}\right| \text { otherwise } \varepsilon_{A M P}=\varepsilon_{1}
$$

where $\varepsilon_{A M P}$ is the absolute maximum principal strain, and $\varepsilon_{1}$ and $\varepsilon_{3}$ are the principal strains.

The Morrow model is used for mean stress $\left(\sigma_{m}\right)$ corrections [20]:

$$
\varepsilon_{a}=\frac{\left(\sigma_{f}^{\prime}-\sigma_{m}\right)}{E}\left(2 N_{f}\right)^{b}+\varepsilon_{f}^{\prime}\left(2 N_{f}\right)^{c}
$$

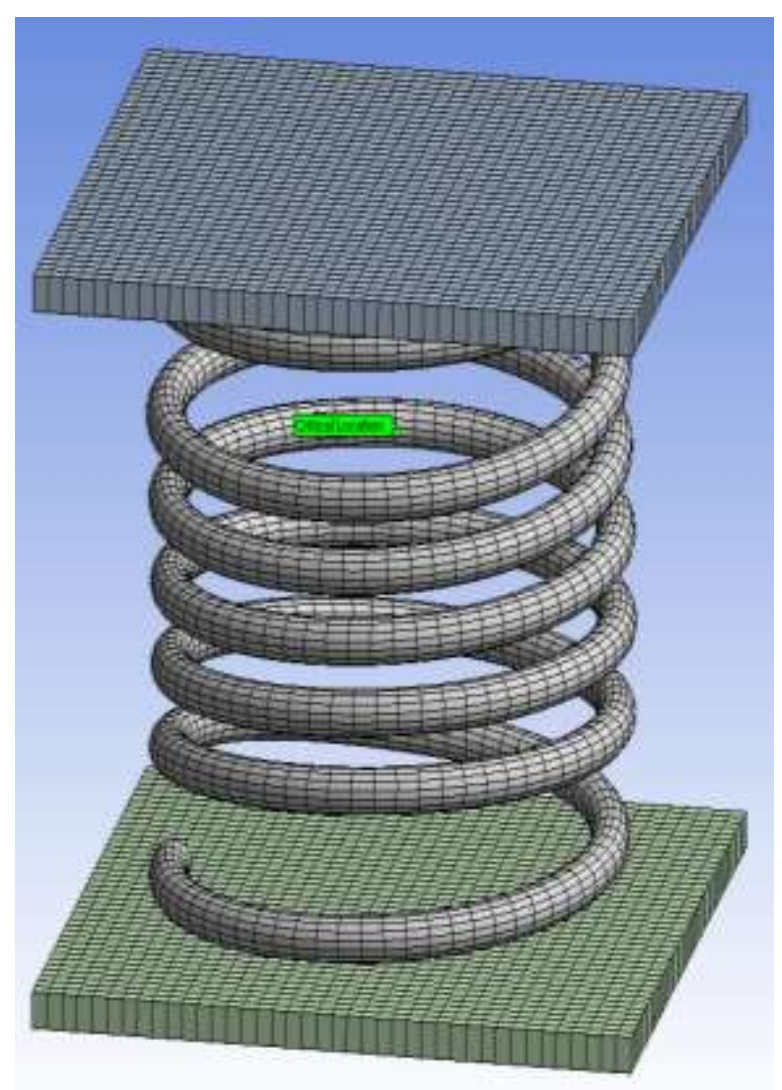

Figure 2. Location of critical region.

\section{RESULTS AND DISCUSSION}

The linear stress analysis was performed utilising finite element analysis software to determine the stress and strain state results. The result of the maximum principal stress is used in the fatigue analysis. Maximum principal stress distribution from the linear static analysis is shown in Figure 3(a). From the results, a maximum principal stress of 776 MPa was obtained at the critical location. The equivalent stress according to von Mises and Tresca criterion at the critical location were calculated as $1479 \mathrm{MPa}$ and $1706 \mathrm{MPa}$, respectively (Table 2), which shows that the spring does not have structural failure as these stress values are far below the yield strength of SAE 9254, i.e. $2257 \mathrm{MPa}$ (Table 1). This makes the fatigue life determination important. Thus, the working life of the spring 
can be known. Moreover, it can be seen from the stress results that there is a sudden change in the maximum principal stress direction at both ends of the spring after one complete turn of the coil. This is in fact due to the contact definition, which assumes that the first turn of the coil is always in contact with the surface geometry used for the application of load on the spring. The fatigue analysis is focused on the results at the critical location and the region around it (Figure 2). This location is selected on the basis of the experimental work by [24] in which they showed that coil spring is failed due to fatigue failure in the active coils far from the inactive coil used as the seat for the spring. The life and damage reported are plotted as contours Figure 3(b-c). It can be seen that the spring will not fail due to fatigue within the design life period of $4 \times 10^{5}$ cycles at the critical location under both time histories [14]. The maximum damage is reported in Figure 3(c) and Figure 4(c) (shown in circular marks). This is because of a geometry modelling discontinuity due to the changing pitch of the coil. Sudden changes in the direction of the coil cause a higher region of stress. As these locations are far from the critical region, their effect is negligible on the results reported at the critical site and can be excluded from the fatigue analysis.

Table 3. Fatigue life at critical location with various methods available

\begin{tabular}{cccc}
\hline \multicolumn{4}{c}{ Fatigue life in cycles $\left(\times 10^{6}\right)}$. \\
Abs. Max. Principal & Signed von Mises & Signed Shear & Critical Plane \\
\hline 52.7 & 0.903 & 0.131 & 57 \\
\hline
\end{tabular}

Table 3 shows the spring lives predicted using different methods. The results agree well with the recommendations for fatigue prediction method selection which are given in Table 4 (where $a_{e}=$ the biaxiality ratio). The biaxiality ratio at the critical location is -0.9 , as shown in Figure 4(a). Therefore, the absolute maximum principal strain is selected as a strain history combination method for fatigue analysis according to the recommended guidelines. From the results, the critical plane is also a valid candidate for analysis, but the required simulation run time is higher as the solver has to search for the critical plane first; as the predicted life is approximately the same from Abs. Max. Strain method, this makes it a better choice for fatigue life estimation.

Table 4. Summarised guide for combination method selection [25]

\begin{tabular}{llll}
\hline & Abs Max. Principal Strain & Signed von Mises & Signed Shear \\
\hline $\begin{array}{l}\text { ae }=-1 \text { (pure shear) } \\
-1<\mathrm{ae}_{\mathrm{e}}<0\end{array}$ & Possible problems with mobility & of principals Use Critical Plane Option \\
& OK & Conservative & Very \\
$\mathrm{ae}_{\mathrm{e}}=0$ (uniaxial) & OK & OK & Conservative \\
$0<\mathrm{a}_{\mathrm{e}}<1$ & Non-Conservative & Non- & OK \\
& & Conservative & OK \\
$\mathrm{ae}=1$ (equibiaxial) & Non-Conservative & OK & OK \\
\hline
\end{tabular}



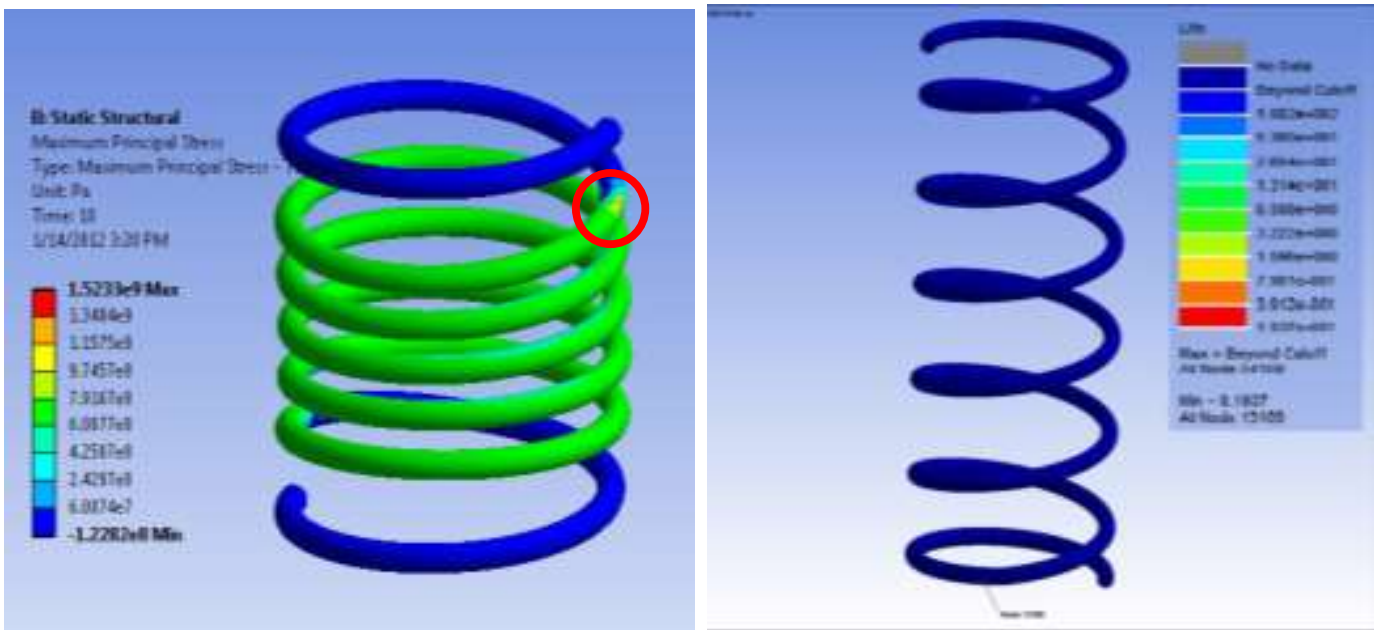

(a) Stress contour

(b) Fatigue life distribution

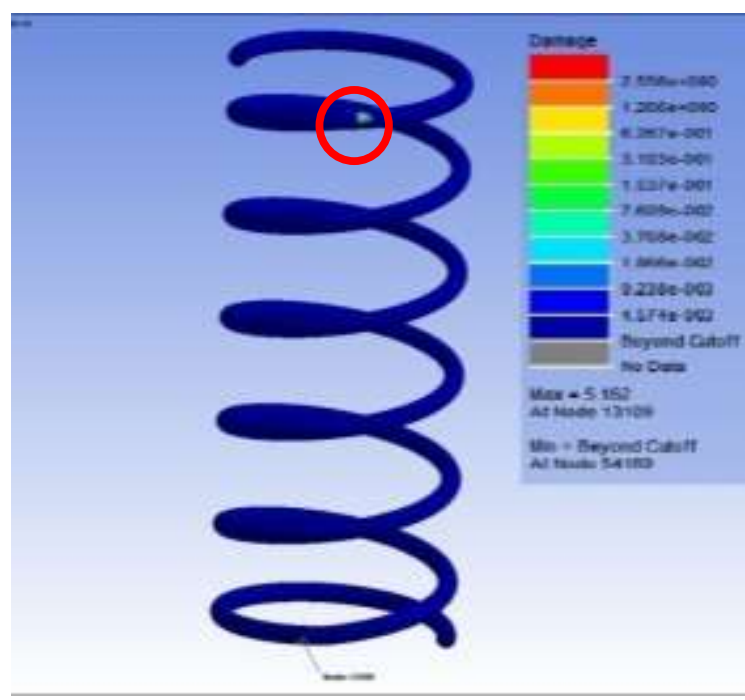

(c) Fatigue damage distribution

Figure 3. Absolute maximum principal stress, fatigue life and damage plot for triangular wave at $4 \mathrm{~Hz}$.

As shown in Table 4, the signed von Mises and signed shear are conservative results and a noticeable reduction in the predicted fatigue life of the spring. The fatigue life of the spring has been predicted using the finite element analysis model. The number of repeats of each time history applied as loading is calculated. For the $4 \mathrm{~Hz}$ triangular wave time history, the fatigue life is obtained at the critical location of $0.516 \times 10^{8}$ cycles. For the SAESUS, the fatigue life is obtained as $0.5271 \times 10^{8}$ cycles. In both loading cases, the life of the spring (the number of cycles) is well above the design life mentioned in the drawing, against which the spring is tested experimentally for the initiation of cracks, and no cracks were found after $4 \times 10^{5}$ cycles. Hence the spring design is safely within its designed fatigue life. 


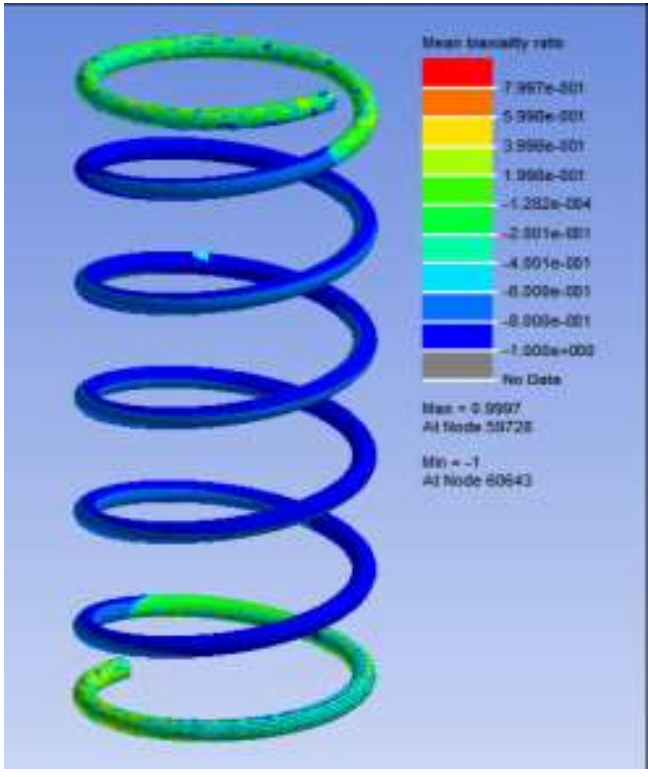

(a) Biaxiality ratio

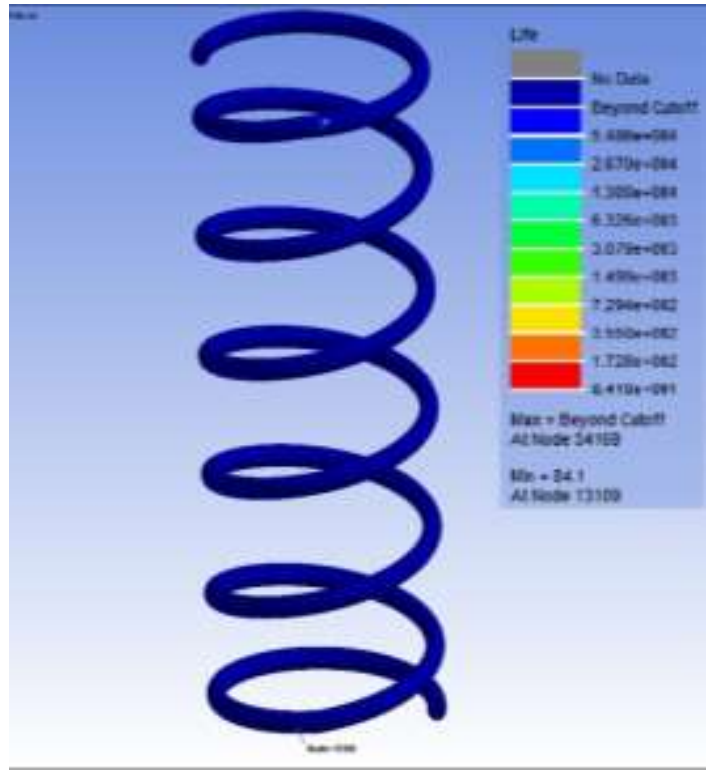

(b) Fatigue life

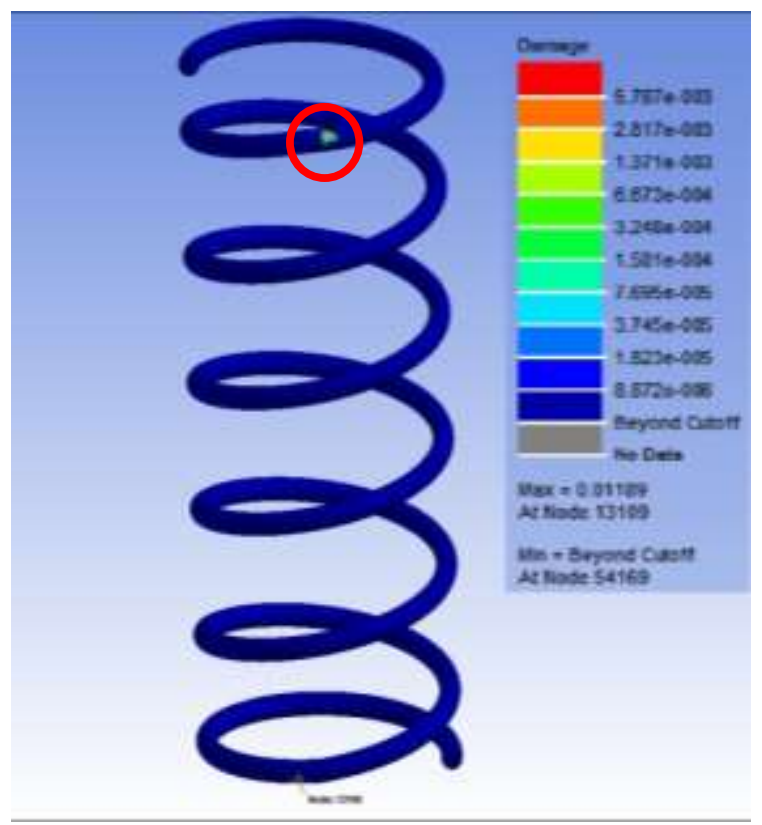

(c) Fatigue damage

Figure 4. Biaxiality ratio and fatigue life and damage plot for SAESUS loading

\section{CONCLUSIONS}

A spring used in shock absorbers from an automotive suspension system has been analysed for fatigue analysis. The material of the spring was the steel alloy SAE 9254. Two time histories were considered as applied loading: one was a triangular wave of $4 \mathrm{~Hz}$ and the other was a standard SAESUS time history. Both are scaled and trimmed according to the design limits mentioned in the vendor drawing. Four methods of strain history combination were evaluated and the absolute maximum principal method was 
found to be suitable for fatigue analysis. The number of cycles required to fail the spring in the case of triangular waves at $4 \mathrm{~Hz}$ and SAESUS time history were found to be $0.516 \times 10^{8}$ and $0.5271 \times 10^{8}$ cycles, respectively. The predicted numbers of cycles were well above the number of cycles mentioned in the design information, i.e. $4 \times 10^{5}$ cycles. Hence the design of the spring can be declared safe under the deformation limits mentioned in the design.

\section{ACKNOWLEDGMENTS}

The authors would like to thank the Universiti Malaysia Pahang for providing laboratory facilities and financial support under the Fundamental Research Grants Scheme (No. RDU130146) and Doctoral Scholarship scheme (GRS140309).

\section{REFERENCES}

[1] Kamal M, Rahman MM, Sani MSM. Application of multibody simulation for fatigue life estimation. International Journal of Automotive and Mechanical Engineering. 2013;7:912-923.

[2] Rahman MM, Ariffin AK, Rejab MRM, Kadirgama K, Noor MM. Multiaxial fatigue behavior of cylinder head for a free piston linear engine. Journal of Applied Sciences. 2009;9:2725-2734.

[3] Rahman MM, Kadirgama K, Noor MM, Rejab MRM, Kesulai SA. Fatigue life prediction of lower suspension arm using strain-life approach. European Journal of Scientific Research. 2009;30:437-450.

[4] Firat M, Kocabicak U. Analytical durability modeling and evaluation complementary techniques for physical testing of automotive components. Engineering Failure Analysis. 2004;11:655-674.

[5] Rahman MM, Ariffin AK, Rejab MRM, Kadirgama K, Noor MM. Multiaxial fatigue behaviour of cylinder head for a free piston linear engine. Journal of Applied Sciences. 2009;9:2725-2734.

[6] Rahman MM, Ariffin AK, Abdullah S, Noor MM, Bakar RA, Maleque MA. Finite element based fatigue life prediction of cylinder head for two-stroke linear engine using stress-life approach. Journal of Applied Sciences. 2008;8:3316-3327.

[7] Rahman MM, Ariffin AK, Jamaludin N, Abdullah S, Noor MM. Finite element based fatigue life prediction of a new free piston engine mounting. Journal of Applied Sciences. 2008;8:1612-1621.

[8] Rahman MM, Ariffin AK, Abdullah S. Finite element based vibration fatigue analysis of a new two-stroke linear generator engine component. International Journal of Mechanical and Materials Engineering. 2007;2:63-74.

[9] Kyrre SA. Fatigue life prediction of an aluminium alloy automotive component using finite element analysis of surface topography: Norwegian University of Science and Technology; 2006.

[10] Popp K, Schiehlen W. Ground vehicle dynamics: Springer; 2010.

[11] Al-Asady NA, Abdullah S, Ariffin AK, Beden SM, Rahman MM. Comparison between experimental road data and finite element analysis data for the automotive lower suspension arm. European Journal of Scientific Research. 2009;29:557-571.

[12] Rahman MM, Mohyaldeen HM, Noor MM, Kadirgama K, Bakar RA. Robust design of suspension arm based on stochastic design improvement. ICMEE 2010 2010 2nd International Conference on Mechanical and Electronics Engineering, 
Proceedings. 2010, p. 1-9.

[13] Rahman MM, Ariffin AK, Jamaludin N, Haron CH. Finite element based durability assessment of a free piston linear engine component. Structural Durability and Health Monitoring. 2007;3:1-13.

[14] Drawings of suspension springVendor. Drawings of suspension spring. 2011.

[15] McClaflin D, Fatemi A. Torsional deformation and fatigue of hardened steel including mean stress and stress gradient effects. International Journal of Fatigue. 2004;26:773-784.

[16] Rahman MM, Ariffin AK, Abdullah S, Jamaludin N. Finite element based durability assessment of a free piston linear engine component. SDHM Structural Durability and Health Monitoring. 2007;3:1-13.

[17] Rahman MM, Ariffin AK, Abdullah S, Noor MM, Bakar RA, Maleque MA. Finite element based fatigue life prediction of cylinder head for two-stroke linear engine using stress-life approach. Journal of Applied Sciences. 2008;8:3316-3327.

[18] Rahman MM, Ariffin AK, Abdullah S, Rosli AB. Effect of nitriding treatment on fatigue life for free piston linear engine component using frequency response method: A finite element approach. SID Structural Integrity and Durability. 2007;3:197-209.

[19] Fatigue life prediction of spot-welded structures: A finite element analysis approachRahman MM, Bakar RA, Noor MM, Rejab MRM, Sani MSM. Fatigue life prediction of spot-welded structures: A finite element analysis approach. European Journal of Scientific Research2008. p. 444-456.

[20] Stephens RI, Fatemi A, Stephens RR, Fuchs HO. Metal fatigue in engineering. New York: John Wiley and Sons, Inc.; 2000.

[21] Matsuishi M, Endo T. Fatigue of metals subjected to varying stress. In: JSME, Fukuoka, Japan. 1968.

[22] Palmgren A. Durability of ball bearings. ZDVDI. 1924;68:p. 339.

[23] Miner MA. Cumulative damage in fatigue. Journal of Applied Mechanics. 1945;67:A159.

[24] Llano-Vizcayaa LD, Rubio-González C, Mesmacque G, Cervantes-Hernández T. Multiaxial fatigue and failure analysis of helical compression springs. Engineering Failure Analysis. 2006;13:1303-1313.

[25] Bishop NWM, Sherratt F. Finite element based fatigue calculations. Netherlands: NAFEMS Ltd.; 2000. 